\title{
Information Technology Governance and the Individual's Behavior: A cross-sectional study
}

\author{
Pedro Fernandes \\ University Institute of Lisbon, Portugal \\ pmvfs1@iscte-iul.pt
}

\section{Rúben Pereira}

University Institute of Lisbon, Portugal

\section{Guilherme Wiedenhöft}

University of Rio Grande, Brazil

\section{Abstract}

Information technology (IT) is increasingly important to organizations and has become essential to the development of sustainable business growth. It is therefore necessary to adopt IT governance (ITG) mechanisms to ensure better solutions, sustainable growth, and better decision-making. As employee behavior is a competitive differential, this work focuses on the behavioral expression of ITG. It aims at analyzing ITG institutionalization's effect on the main dimensions of Organizational Citizenship Behavior (OCB) in Portugal. OCB describes individuals' voluntary commitment to an organization, including attitudes outside of their contractual functions. A descriptive-confirmative ex post facto research was conducted through survey research to 112 employees of IT-related departments and divisions from companies of all sizes in Portugal. The partial least square-structural equation modeling (PLS-SEM) method was used to test the overall model. The general hypothesis was confirmed, showing that ITG institutionalization positively affects individuals' OCBs in Portuguese organizations. In practical terms, it is possible to show organizations that by implementing their ITG Mechanisms, they are increasing employees' OCBs and, consequently, organizational effectiveness.

Keywords: IT Governance; ITG Mechanisms; Organizational Citizenship Behavior; Partial Least Squares (PLS-SEM).

\section{Introduction}

Information technology (IT) is increasingly important to organizations and has become essential to the development of sustainable business growth. Furthermore, it is almost impossible for organizations in today's global digital economy to be competitive and innovative without investing in IT (ITGI, 2003; Van Grembergen \& De Haes, 2018).

Organizations must be conscious of the importance of governing IT instead of only managing it. Therefore, it is necessary to involve IT Governance (ITG) processes (Brandi \& Malheiro da Silva, 2017). While IT management involves short term aspects and focuses on the management of IT operations, ITG deals with long term and external aspects, performing and transforming IT to meet current and future demands of the business's and stakeholders' expectations (Brown \& Magill, 1994; De Haes \& Van Grembergen, 2004; Wiedenhöft et al., 2019). Therefore, ITG is no longer considered a "nice-to-have" but a "must-have" (Webb et al., 2006; Pereira \& Mira da Silva, 2012a). 
ITG is how organizations strategically align IT with business (Schwarz \& Hirschheim, 2003; Amali et al., 2018). It is part of enterprise governance and consists of leadership, organizational arrangements, patterns, and processes that ensure the development and maintenance of effective IT control and accountability, performance, and risk management. Plus, ITG proposes that the organization's IT sustains and extends its strategy and objectives (Hardy, 2006; ITGI, 2003; Jacobson, 2009; Sambamurthy \& Zmud, 1999; Webb, 2006). Finally, it is also part of ITG's role to consider the organization's cultural differences since the national culture can influence its dimensions (Pereira \& Mira da Silva, 2012a; Zhong et al., 2012).

Some recent studies, like those of Juiz, Guerrero, \& Lera (2014), Juiz \& Toomey (2015), Luciano, Wiedenhöft, Macadar, \& Pinheiro dos Santos (2016), and Wiedenhöft et al. (2017), suggest adopting ITG mechanisms based in two orientations. On the one hand, the most widely studied is focused on the process side, which refers to crucial IT strategic decisions and monitoring key roles and responsibilities (Van Grembergen et al., 2004; Bartenschlager \& Goeken, 2010). On the other hand, the focus is on the behavioral side of ITG, which is related to individuals dealing with IT-related decisions and activities (Huang et al., 2010; Tiwana et al., 2013). As Weill \& Ross (2004) argue, ITG mechanisms must encourage individuals who use IT to follow the desired behavior.

Since IT has become vital to businesses' sustainability, support, and growth, organizations increasingly depend on it (Pereira \& Mira da Silva, 2012; Pereira \& Mira da Silva, 2012b; Van Grembergen \& De Haes, 2018). However, an advantageous competitive differential lies in its employees' behavior (P. M. Podsakoff \& MacKenzie, 1997).

It is important to clearly define the encouragement given to get a desirable behavior, ensuring effective governance (Juiz et al., 2014). Good behavior contributes to a more consistent and aligned relationship between business and IT (Van Grembergen, 2004), while poor human behavior can defeat the best ITG institutionalization process (Juiz \& Toomey, 2015). This research focuses on the behavioral side of ITG, acknowledging its importance.

Organizational Citizenship Behavior (OCB) works as a global measure of individual behavior at work, and it is used in this study to understand individuals' behavior (Graham, 1991). Organ $(1989,1997)$ defines and reviews OCB, describing it as a voluntary commitment and those individuals' behaviors that benefit the organization, though not being part of their contractual tasks and not formally rewarded by the organization's gratification system.

Based on ITG and OCB concepts, this research aims to understand and test the effects of Portuguese culture on the relationships between them, as well as to analyze how citizenship behavior can be affected by ITG institutionalization.

The cultural context is one of the main problems and a source of great motivation to this research, becoming important the study of its impact on ITG and OCB concepts. According to P. M. Podsakoff et al. (2000), the cultural context may have distinct impacts on citizenship behavior. In comparison, according to Pereira \& Mira da Silva (2012), contingency factors influence organizations' ITG implementation. One of these factors is the "Regional Differences," where aspects such as language, local laws, and national information infrastructures impact the ITG implementation (Weisinger \& Trauth, 2003).

As a part of the Latin Europe cluster, the Portuguese culture is centered on the dimensions of femininity, high power distance, high collectivism, and low-performance orientation 
(Hofstede, 1989; Jesuino, 2002; A. A. Rego et al., 2010; Hofstede, 2011). According to Ferreira, Braun, \& Sydow (2013), the Portuguese culture promises to relate well with citizenship behaviors. However, Kowal, Keplinger, \& Mäkiö (2019) and Armenio Rego \& Pina e Cunha (2010) indicate a lack of studies on OCB in the Portuguese context, describing it as an "understudied context," arguing that most of the studies were performed in the USA, Asia, and Northern Europe.

In order to contribute to this literature gap and to study the relationship between ITG and OCB in Portuguese organizations, the research question is:

- Does the adoption of ITG mechanisms affect positively or negatively the individuals' behavior in Portuguese organizations concerning OCB?

To answer this question and achieve the proposed goal, it is essential to carry out in-depth research. A descriptive-confirmative ex post facto research will be developed during this study, materialized in a survey to be answered by workers of IT-related departments and divisions from companies of all sizes in Portugal. According to Pereira (2014), Portuguese organizations have already begun implementing their ITG mechanisms, so now is the right moment to carry out this study using the research methodology mentioned above.

This article has the following structure: An introductory section that introduces the research theme and its purpose. The theoretical background section reviews the literature about OCB and ITG concepts and synthesizes what has previously been studied. The next section describes the theoretical model, constructs, and hypotheses tested in this research, and is followed by a section that presents the details of the applied research method. The data analysis section includes the evaluations and explanations of the survey results using the PLSSEM method. Finally, the discussion and conclusion section presents the main research findings. It also discusses the hypothesis tests' results and limitations and offers suggestions for future research.

\section{Theoretical background}

\subsection{IT governance}

According to De Haes et al. (2020), "governance of information technology" is a relatively new subject in the academic and professional literature. Some pioneers in this matter, such as Loh and Venkatraman (1992), acknowledged the importance of ITG as part of the organization's IT strategy. Since then, the topic has caught authors' attention, causing a considerable growth in ITG literature. Despite that, authors diverge on the definition of ITG, proving a lack of shared knowledge in this subject (Pereira \& Mira da Silva, 2012b). In 2004, Weill and Ross (2004) defined ITG as a way of encouraging individuals' desirable behavior in the use of IT. This definition was widely used in the academic and professional world and recognized as the behavioral side of ITG. However, it has been replaced over the years by a much more complete one, which links ITG to corporate governance and business. One example is the definition of ITG from De Haes et al. (2020): "ITG is an integral part of corporate governance for which, as such, the board is accountable. It involves the definition and implementation of processes, structures, and relational mechanisms that enable both business and IT stakeholders to execute their responsibilities in support of business/IT alignment, and the creation and protection of IT business value." 
Commonly seen as part of corporate governance (Weill \& Ross, 2004), ITG applies corporate governance concepts to strategically drive and control IT on two key issues: the value that IT provides to an organization and the control and mitigation of IT-related risks (Van Grembergen, 2004; Hardy, 2006). Consequently, effective implementation of ITG models can guarantee the organization's needs and objectives in leadership and accountability of the management board (Amali et al., 2018).

Effective ITG ensures return on IT investments and improves organizational performance. Since IT investments are a significant part of corporate budgets, good ITG models generate business value and mitigate the associated risks (Jacobson, 2009; Lunardi et al., 2009; Pereira \& Mira da Silva, 2012b; Juiz \& Toomey, 2015).

With regards to IT, ITG helps to define a direction for and control of IT operations by specifying decision-making structures, processes, and relational mechanisms (Sambamurthy \& Zmud, 1999). ITG amplifies organizational IT agility when aligned with IT unit choices and their departments' peripheral knowledge (Tiwana \& Kim, 2015). Considering its strategic importance, managing IT is insufficient; it is necessary to govern IT (Wiedenhöft et al., 2019).

\subsection{Organizational citizenship behavior}

OCB is characterized as an act of social exchange offered voluntarily by workers to organizations (Organ, 1988). They are spontaneous gestures of collaboration and protective actions to safeguard the organization and everything related to it (A. Rego, 2002). These voluntary actions are exempt from legal or contractual prescriptions. When executed, they allow a social relationship with the organization, initiating an exchange of functional extrapolitical acts that will possibly lead to a hypothetical future social, material, or economic remuneration. They are composed of employees' social acts which benefit the employer system and may or may not get rewards from the organization (Smith et al., 1983; Siqueira, 2003).

Besides OCB, there are other similar models built and validated that allow measuring individual behavior (Matias Siqueira, 2002), like prosocial behavior (Brief \& Motowidlo, 1986), civic virtue (Graham, 1991), and organizational commitment (Borges-Andrade, 1994). However, it is possible to find significant differences between those concepts (P. M. Podsakoff et al., 2000). This study uses OCB like Luciano et al. (2016) and Wiedenhöft et al. (2017) did, taking into account the possible relationship with the desirable behavior encouraged by Corporate Governance and, consequently, ITG. According to Organ (1989), OCB is connected with job performance because citizenship behaviors are part of the spontaneous and innovative behaviors essential for effective organizations (Katz \& Kahn, 1978).

While there is a broad consensus about OCB as discretionary behaviors of individuals helping the organization, this consensus does not apply to all the OCB domains. Thus, in the early 2000s, more than 30 OCB dimensions were reported in the literature (P. M. Podsakoff et al., 2000). A few years later, this number had more than doubled, and it tends to increase (N. P. Podsakoff et al., 2014). Such dimensions are essential for measuring distinct OCB manifestations (Graham, 1991). On this basis, a summary of OCB's main dimensions found in the literature and their definitions are presented below:

- Altruism: Voluntary actions that help others with a work problem.

- Civic Virtue: Behaviors related to the individual involved or concerned about the company's life. 
- Conscientiousness: An excellent posture of going well beyond minimally required levels of attendance, punctuality, housekeeping, conserving resources, and internal maintenance issues.

- Sportsmanship: Good behavior of the individual who tolerates the inevitable inconveniences and demands of work without complaint.

- Helping Behavior: Focuses on helping coworkers in their jobs when it is needed.

- Courtesy: Individuals' discretionary behavior aiming to prevent work-related problems from happening.

- Loyalty: Identification with and loyalty to the organization's leaders and the organizations' individuals, workgroups, and departments' local interests.

- Individual Initiative: Refers to a proactive and spontaneous effort to solve problems and improve individual and group performance.

- Organizational compliance: The acceptance and respect for rules and procedures in the organization.

- Identification with the organization: Shows how the individual defends the organization's image to outsiders.

- Interpersonal harmony: Individuals' discretionary behavior aiming to prevent workrelated problems from happening.

\section{Theoretical Model}

This section formulates and discusses the theoretical model, its constructs, and the hypotheses tested in this research, providing a roadmap for the remainder of the study.

The study's general hypothesis demonstrates how ITG institutionalization positively affects individuals' OCBs in Portuguese organizations. Previous research on OCB correlates good behaviors with a set of informal individual contributions that benefit the organization (Organ, 1988; Matias Siqueira, 2002). This type of behavior is essential to guarantee conformance with the most delicate process models and to improve non-effective process models. Furthermore, bad behavior can defeat even the best process models (Juiz \& Toomey, 2015).

ITG and its mechanisms, an essential part of corporate governance regarding its IT-related aspirations, are fundamental to encourage desired behavior from employees towards the use of IT (Weill \& Ross, 2004; De Haes \& Van Grembergen, 2008). Wiedenhöft et al. (2017) stated that the ITG institutionalization process acts in OCB's antecedents, like job satisfaction and rewards perception.

This argument combines the influence of ITG institutionalization processes on individuals' behavior with the organization's performance, sustaining a perspective of a recurrent positive effect on the organization.

On this background, this study's research model is built upon an ITG institutionalization model that has been derived from previous research (see Luciano et al., 2016 and Wiedenhöft et al., 2017), specified in Table 1, in conjunction with Arménio Rego's (1999) OCB model presented in Table 2. This OCB model was designed and operationalized for the Portuguese 
context and has been used in previous research (Wiedenhöft et al., 2017; A. Rego, 2002; A. Rego \& Pina e Cunha, 2008; A. A. Rego et al., 2010).

\begin{tabular}{|c|c|c|}
\hline \multicolumn{3}{|c|}{ The ITG institutionalization model } \\
\hline Variable & Definition & Origin \\
\hline $\begin{array}{l}\text { ITG effectiveness } \\
\text { perception (Cultural- } \\
\text { Cognitive } \\
\text { Institutionalization) }\end{array}$ & $\begin{array}{l}\text { Variable related to the cultural-cognitive } \\
\text { institutionalization of ITG, which aims to analyze if the } \\
\text { individuals perceive the efficiency of adopting ITG } \\
\text { mechanisms. }\end{array}$ & $\begin{array}{l}\text { Institutionalization } \\
\text { Model built based on } \\
\text { models of Luciano et al. } \\
\text { (2016), Scott (2008) and }\end{array}$ \\
\hline $\begin{array}{l}\text { ITG mechanisms } \\
\text { (Regulatory } \\
\text { Institutionalization) }\end{array}$ & $\begin{array}{l}\text { Variable related to the regulatory institutionalization of } \\
\text { ITG. The individual perceives the adoption of ITG } \\
\text { mechanisms to establish rules, monitoring, and sanctions. }\end{array}$ & Wiedenhöft et al. (2017). \\
\hline $\begin{array}{l}\text { ITG structure } \\
\text { formalization } \\
\text { (Normative } \\
\text { Institutionalization) }\end{array}$ & $\begin{array}{l}\text { Variable related to the normative institutionalization of } \\
\text { ITG. The individual realizes the formalization of the ITG } \\
\text { structure as a normative system of impositions on social } \\
\text { behavior, authorizing and enabling social action. }\end{array}$ & \\
\hline
\end{tabular}

Table 1. The ITG institutionalization model variables

\begin{tabular}{|l|l|l|}
\hline \multicolumn{2}{|c|}{ The OCB model } \\
\hline Variable & Definition & Origin \\
\hline Conscientiousness & $\begin{array}{l}\text { Variable related to an excellent posture of going well } \\
\text { beyond minimally required levels of attendance, } \\
\text { punctuality, housekeeping, conserving resources, and } \\
\text { internal maintenance issues. }\end{array}$ & $\begin{array}{l}\text { Developed and } \\
\text { validated by Arménio } \\
\text { Rego (1999) in } \\
\text { Portugal. }\end{array}$ \\
\cline { 1 - 2 } Individual initiative & $\begin{array}{l}\text { Variable connected to a proactive and spontaneous effort to } \\
\text { solve problems and improve individual and group } \\
\text { performance. }\end{array}$ & \\
\cline { 1 - 2 } $\begin{array}{l}\text { Identification with } \\
\text { the organization }\end{array}$ & $\begin{array}{l}\text { The variable that shows how the individual seeks to defend } \\
\text { the organization's image to outsiders. }\end{array}$ & \\
\cline { 1 - 2 } $\begin{array}{l}\text { Interpersonal } \\
\text { harmony }\end{array}$ & $\begin{array}{l}\text { Variable related to behaviors that aim to prevent work- } \\
\text { related problems from happening. }\end{array}$ & \\
\hline
\end{tabular}

\section{Table 2. The OCB model variables}

This research proposes that the resulting model relates the ITG institutionalization model to the four OCB variables, as presented in Figure 1. It also puts forward the following four hypotheses that will subsequently be tested:

H1: The ITG institutionalization model positively influences an individual's OCB behavior of conscientiousness.

H2: The ITG institutionalization model positively influences an individual's OCB behavior of interpersonal harmony.

H3: The ITG institutionalization model positively influences an individual's OCB behavior of identification with the organization.

H4: The ITG institutionalization model positively influences an individual's OCB behavior of individual initiative. 


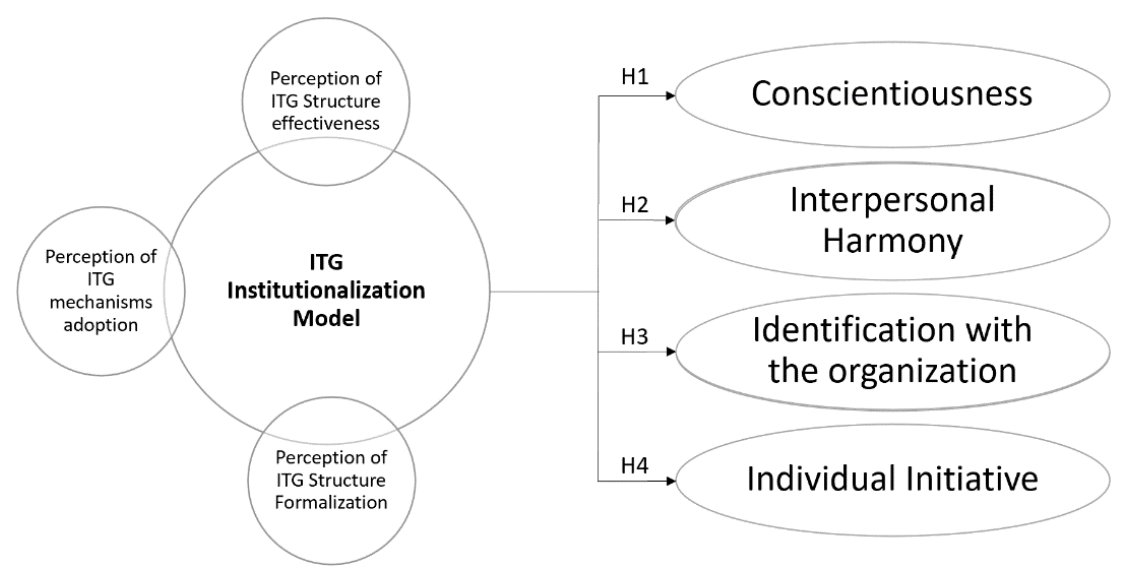

Figure 1. The research model

\section{Research method}

This research is performed with a functionalist epidemiology with the aim to understand a phenomenon in a way that can generate knowledge to be used by organizations (Deetz, 1996). This study is an ex post facto research with a descriptive design and a confirmatory nature. The data collection and analysis were performed as a cross-sectional study (Venkatesh et al., 2013). Figure 2 presents the research design.

\begin{tabular}{|c|}
\hline $\begin{array}{c}\text { Exploratory- } \\
\text { Descriptive Phase }\end{array}$ \\
$\begin{array}{l}\text { - Literature review to define the } \\
\text { concepts (ITG and OCB). }\end{array}$
\end{tabular}$\Rightarrow$\begin{tabular}{|l|l|}
\hline Data collection \\
$\begin{array}{l}\text { Purvey made to IT-related } \\
\text { departments and divisions from } \\
\text { companies in Portugal. }\end{array}$ \\
Phase
\end{tabular}

Figure 1. The research design model

Given the nature of the problem, as well as the context and purpose of this study, a survey research method was deemed suitable since it provides the possibility to study a population sample and generalize (Glasow, 2005). A survey instrument works as a measurement object that links the objectives initially defined in a study with measurable variables that will help normalize and control the data to obtain the most accurate and reliable information (Visser et al., 1986; Ponto, 2015).

Therefore, a survey instrument was developed and administered in IT-related departments and divisions from companies of all sizes in Portugal from June to October 2019. No specific criteria, such as size or type of industry, were established for companies to participate in this study since the study's objective was to investigate individuals' organizational behavior. The only prerequisites were that the organization was located in Portugal and had ITG mechanisms implemented. As for employees, everyone who worked in the company for more than a year could participate to ensure respondents' familiarity with its ITG institutionalization. 
This research adopted the questionnaire developed and validated by Wiedenhöft et al. (2017) in Brazil. It was adapted to Portugal's Portuguese linguistic terms, but it retained the original structure to enable the comparison of results. The questionnaire and its relation to all item codes are presented in the next chapter in Table 5 and Table 6.

Many benefits can emerge from using and adapting this questionnaire, starting with the fact that both studies used the same model, which was built considering the operationalization of the variables presented in Table 1 and Table 2. Also, this questionnaire has the advantage of having already been tested and validated. Therefore, a future test will only ensure that the questionnaire works and guarantee data compliance. Finally, the use of this questionnaire still opens the door to a multicultural cross-study analysis, giving the readers the possibility to understand how this method might work in other countries and how the individual's behavior changes according to its national context.

The distribution channel used to deliver the questionnaire to the workers of various organizations was the Internet. The Internet was the best communication channel to achieve this research's objectives with such a large and geographically dispersed population. The questionnaire was placed online using Google Forms. For this study's purpose and since it is used in scientific projects worldwide, this tool fulfilled all the requirements regarding information security and statistical functionalities (Curts, 2013). At the end of the data collection procedure, a set of 116 surveys had been completed. For ethical reasons and by the organizations' request, the questionnaires were anonymous, making it impossible to identify the workers and organizations participating in the questionnaire. Table 3 shows the respondents' profiles.

\begin{tabular}{|c|c|c|c|}
\hline \multicolumn{2}{|c|}{ Social-demographic variables } & Frequency & Percentage (\%) \\
\hline \multirow{3}{*}{ Gender } & Male & 80 & 71 \\
\cline { 2 - 4 } & Female & 32 & 29 \\
\hline \multirow{3}{*}{ Age } & $18-35$ years & 59 & 52 \\
\cline { 2 - 4 } & $36-45$ years & 51 & 46 \\
\cline { 2 - 4 } & $>55$ years & 2 & 2 \\
\hline \multirow{3}{*}{ Education } & High school & 21 & 59 \\
\cline { 2 - 4 } & Bachelor's & 66 & 22 \\
\cline { 2 - 4 } & Master's & 25 & 6 \\
\hline \multirow{3}{*}{$\begin{array}{c}\text { Total employees in the } \\
\text { organization }\end{array}$} & $01-50$ & 7 & 26 \\
\cline { 2 - 4 } & $51-100$ & 29 & 51 \\
\cline { 2 - 4 } & $101-500$ & 57 & 17 \\
\hline \multirow{3}{*}{$\begin{array}{c}\text { Total employees in the IT } \\
\text { department }\end{array}$} & $>1000$ & 19 & 23 \\
\cline { 2 - 4 } & $01-10$ & 26 & 29 \\
\cline { 2 - 4 } & $11-50$ & 32 & 28 \\
\cline { 2 - 4 } & $51-100$ & 31 & \\
\hline
\end{tabular}

Table 3. Respondents' profile

A three-phase examination was carried out to make a selection from the data. First, the author had to ensure that the survey respondents were familiar with the theme of the research. Second, to guarantee the answers' reliability, the respondents should have been employed in the organization for longer than a year or have at least two years of professional experience. 
Finally, following Joseph et al.'s (2014) statements, the data must be verified to exclude missing values, suspicious response patterns, and outliers. At the end of the data cleansing procedure, 112 good results were obtained, corresponding to $97 \%$ of the surveys.

\section{Data analysis}

This section evaluates the survey outcomes, presenting the results of the hypotheses proposed in the previous section. The Partial Least Square (PLS)-Structural Equation Modeling (SEM) (PLS-SEM) method was used to test the overall model. As the Kolmogorov-Smirnov test shows, it is not possible to determine the normality of the sample, so the PLS-SEM method was chosen because it is the one that best suits the needs of this study. For example, PLS-SEM fits well when sample sizes are not too large, the data are nonnormally distributed, and the purpose of the study is to explain the relationships between multiple variables in complex models (Hair et al., 2011; Hair Jr. et al., 2014, 2018).

Figure 3 presents the three types of analysis and the tests that were performed for the study.

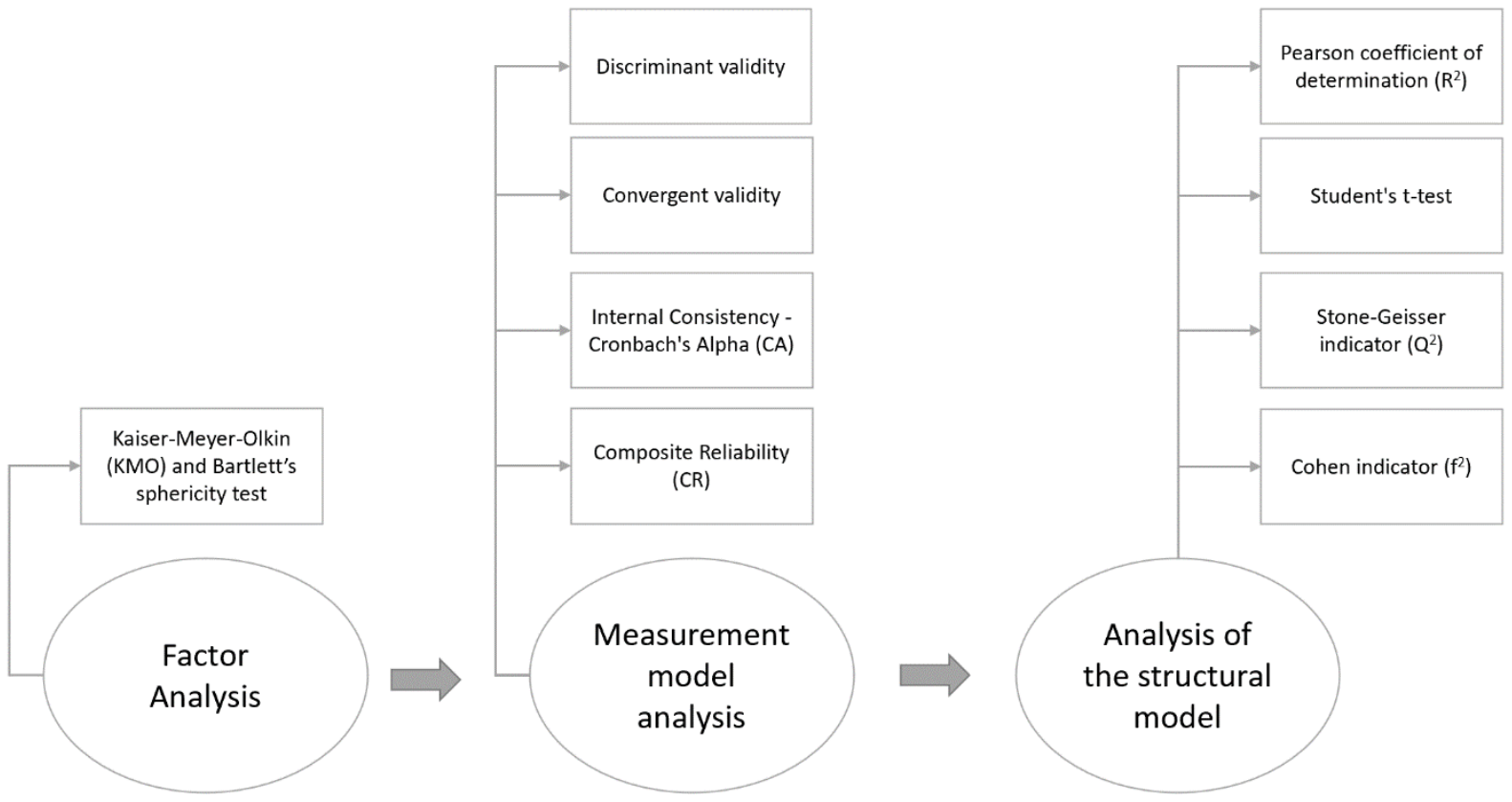

Figure 3 - Data analysis structure

\subsection{Factor analysis}

As stated in the previous section, a pre-test was not performed to validate the instrument for two reasons. On the one hand, Wiedenhöft et al. (2017) have already validated the instrument in their study. On the other hand, the sample size is not big enough to be split in a pre-test analysis. Despite this, the Kaiser-Meyer-Olkin (KMO) and Bartlett's sphericity test was run to measure the adequacy of the samples. The IBM SPSS (Statistical Package for the Social Sciences) Statistics Software was used to run the tests.

According to the existing literature, a KMO statistics test should be above 0.5 (Field, 2009). As Table 4 shows, for the analysis, $\mathrm{KMO}=0.858$ ('great' according to Field (2009)) and for Bartlett's test of sphericity, the approximate Chi-square is 2635.842 with 528 degrees of freedom, which 
is significant at this level (Sig. $<.05$ according to Field (2009)). Therefore, it is credible to conclude that the data is appropriate for factor analysis.

\begin{tabular}{|l|l|l|}
\hline \multicolumn{2}{|l|}{} \\
\hline Kaiser-Meyer-Olkin Measure of Sampling Adequacy & $\mathbf{0 . 8 5 8}$ \\
\hline Bartlett's Test of Sphericity & Approximate chi-square & 2635.842 \\
\hline & Degree of freedom & 528 \\
\hline & Significance & 0,000 \\
\hline
\end{tabular}

Table 4. Kaiser-Meyer-Olkin and Bartlett Tests

\subsection{Measurement model analysis}

To evaluate the reliability and validity of the items and the constructs in the measurement model, the author used SmartPLS Software, a friendly and prominent path modeling tool for PLS-SEM applications (Wong, 2013; Ringle et al., 2014). The models were built with this software, and it was used to verify the discriminant and convergent validity and the item and composite reliability. To simplify the interpretation of the model, Table 5 and Table 6 (see below) explain the variables used.

The first-order model was constructed by linking each of the three latent variables of the ITG institutionalization model to the four latent variables of the OCB model. It also connects the latent variables with the several observable variables that correspond to each one of the questions in the questionnaire.

Finally, after loading the data and completing the model's design, the PLS Algorithm was calculated. The "PLS Algorithm - Setup" was configured according to Ringle et al. (2014) and Wong's (2013) recommended parameters: (1) Weighting scheme: Path weighting scheme (2) Data metrics: (2.1) Mean: 0 (2.2) Variance: 1 (3) Maximum iterations: 300 (4) Abort criterion: 1.0E-5. (5) Initial weights: 1.0.

Figure 4 (see below) shows the results of the calculations and the first-order model of the SmartPLS Software constructs. As Ringle et al. (2014) recommend, the critical values in this section are highlighted.

The next step of the analysis consists of evaluating the reliability and validity of the items and constructs in the measurement model. First, it starts with discriminant validity, aiming to ensure that latent variables are independent of each other (Hair Jr. et al., 2014). This study follows two methods to measure discriminant validity. One must assess its validity by examining the observable variables' cross loads (Hair Jr. et al., 2014). Table 7 (see below) shows the discriminant validity test, considering the Cross Loading Analysis (Chin, 1998).

The results of the Cross Loading Analysis show us that most of the factorial loads of observed variables are higher in the corresponding latent variables than the others. The exception occurs in the ITGM variable, in which two factors $(0.642$ and 0.634$)$ are slightly smaller $( \pm 0.032$ or $3.2 \%$ of variance) than the other two factors (0.666 and 0.659) from the ITG_FORM variable. These occur between them because they are related and are a cause and effect of each other. One way of solving this was removing the lower observable indicators from ITGM and recalculating the model to ensure the independence of latent variables. However, the indicated values have slight differences, and it is expected that there is some degree of overlap between the ITG 
institutionalization model variables' factors. Thus, the instrument's discriminant validity was confirmed, considering the Cross Loading Criterion (Chin, 1998).

\begin{tabular}{|c|c|c|c|c|}
\hline & Dimension & Question variable & Question intro & Question item \\
\hline & \multirow{10}{*}{$\begin{array}{l}\text { ITG } \\
\text { Mechanisms (ITGM) }\end{array}$} & ITGM_Q1 & \multirow{10}{*}{$\begin{array}{l}\text { Regarding the adoption of the IT } \\
\text { Governance Model, I believe the } \\
\text { organization I work for has: }\end{array}$} & $\begin{array}{l}\text { IT structure or steering } \\
\text { committee. }\end{array}$ \\
\hline & & ITGM_Q2 & & $\begin{array}{l}\text { Formalized IT } \\
\text { organizational structure. }\end{array}$ \\
\hline & & ITGM_Q3 & & $\begin{array}{l}\text { Risk analysis structure or } \\
\text { committee. }\end{array}$ \\
\hline & & ITGM_Q4 & & $\begin{array}{l}\text { Structure or committee for } \\
\text { managing IT projects. }\end{array}$ \\
\hline & & ITGM_Q5 & & IT performance indicators. \\
\hline & & ITGM_Q6 & & $\begin{array}{l}\text { Sets of IT management, } \\
\text { control, and evaluation } \\
\text { practices. }\end{array}$ \\
\hline & & ITGM_Q7 & & $\begin{array}{l}\text { Set of practices for } \\
\text { information security. }\end{array}$ \\
\hline & & ITGM_Q8 & & $\begin{array}{l}\text { Methods for assessing IT } \\
\text { strategic alignment levels. }\end{array}$ \\
\hline : & & ITGM_Q9 & & $\begin{array}{l}\text { Physical space / Office for IT } \\
\text { Governance team or } \\
\text { equivalent. }\end{array}$ \\
\hline & & ITGM_Q10 & & $\begin{array}{l}\text { Knowledge exchange } \\
\text { practices. }\end{array}$ \\
\hline 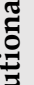 & \multirow{6}{*}{$\begin{array}{l}\text { ITG effectiveness } \\
\text { perception } \\
\text { (ITG_EFEC_PER) }\end{array}$} & ITG_EFEC_PER_Q1 & \multirow{6}{*}{$\begin{array}{l}\text { Regarding the IT Governance } \\
\text { Mechanisms in the organization } \\
\text { where I work, I believe they: }\end{array}$} & $\begin{array}{l}\text { Provide customer-focused } \\
\text { IT services. }\end{array}$ \\
\hline 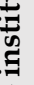 & & ITG_EFEC_PER_Q2 & & $\begin{array}{l}\text { Provide integration between } \\
\text { systems and processes. }\end{array}$ \\
\hline & & ITG_EFEC_PER_Q3 & & $\begin{array}{l}\text { Promote collaborative and } \\
\text { knowledge-sharing } \\
\text { networks. }\end{array}$ \\
\hline & & ITG_EFEC_PER_Q4 & & $\begin{array}{l}\text { Guarantee the optimization } \\
\text { of resources in the IT area. }\end{array}$ \\
\hline & & ITG_EFEC_PER_Q5 & & $\begin{array}{l}\text { Focus the IT Governance } \\
\text { mechanisms on customers' } \\
\text { needs. }\end{array}$ \\
\hline & & ITG_EFEC_PER_Q6 & & $\begin{array}{l}\text { Promote integration } \\
\text { between the different } \\
\text { organisms of the } \\
\text { organization. } \\
\end{array}$ \\
\hline & \multirow{2}{*}{$\begin{array}{l}\text { ITG structure } \\
\text { formalization } \\
\text { (ITG_FORM) }\end{array}$} & ITG_FORM_Q1 & \multirow[t]{2}{*}{$\begin{array}{l}\text { Regarding the formalization of } \\
\text { the IT Governance Model: }\end{array}$} & $\begin{array}{l}\text { The organization where I } \\
\text { work has an IT Governance } \\
\text { model. }\end{array}$ \\
\hline & & ITG_FORM_Q2 & & $\begin{array}{l}\text { The IT Governance Model in } \\
\text { the organization is } \\
\text { formalized. }\end{array}$ \\
\hline
\end{tabular}

Table 5. Explanation of the ITG institutionalization model variables 


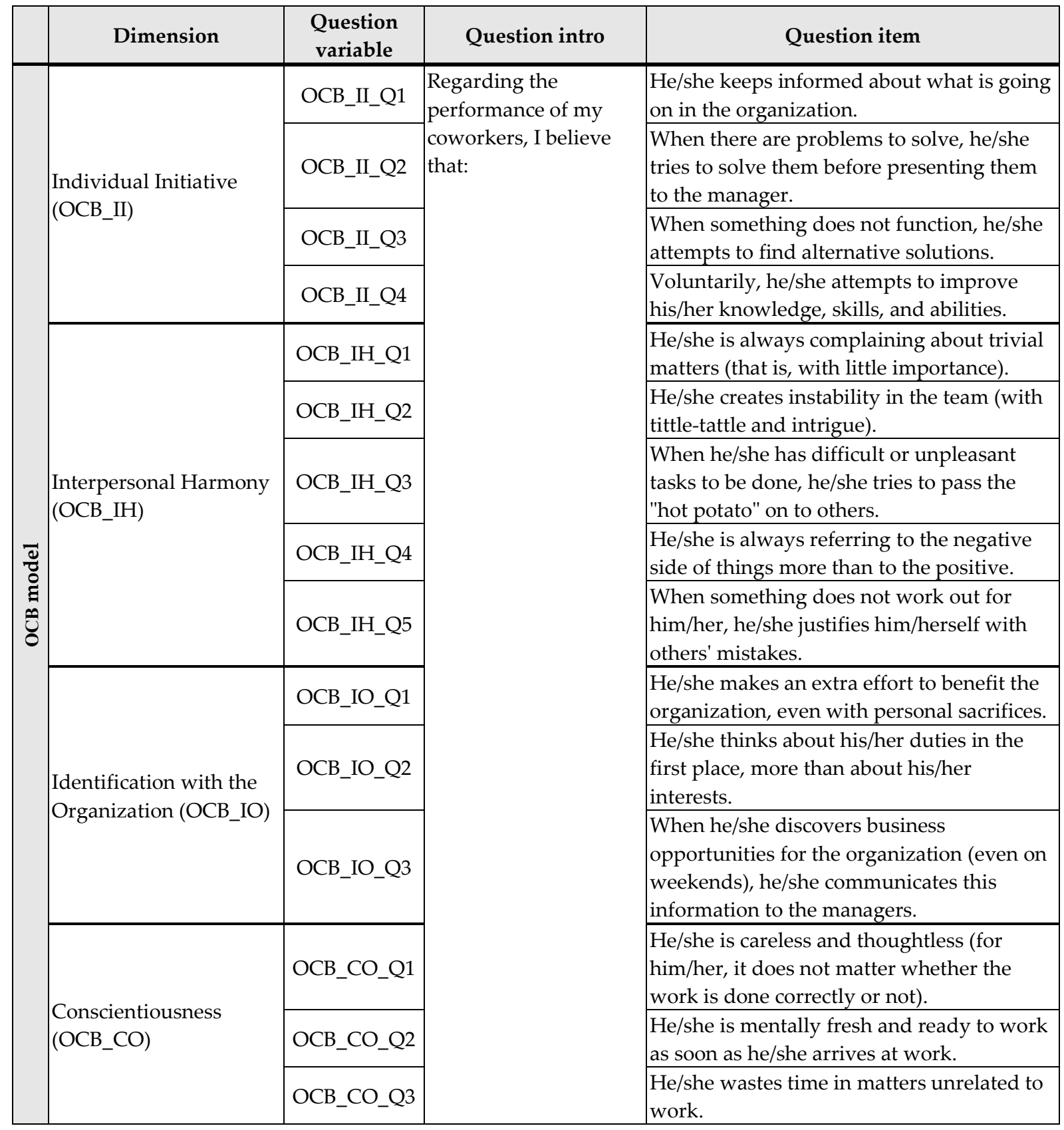

Table 6. Explanation of the OCB model variables

As the validity of our model continues to advance, Table 8 (see below) shows the discriminant validity test, considering the Fornell \& Larcker (1981) criterion. Fornell \& Larcker (1981) suggest that the square root of the Average Variance Extracted (AVE) in each latent variable can be used to prove discriminant validity if this value is higher than other correlation values between the latent variables (Wong, 2013).

Table 8 shows that each one of the latent variables shares better variance with its associated indicators than with any other indicator, which confirms the statement in Table 7 about the discriminant validity of the model. Finally, the values were analyzed in order to determine the Internal Consistency - Cronbach's Alpha (CA), Composite Reliability (CR), and convergent validity (AVE). Following Jr., C. Black, et al. (2014) recommendations, Table 9 (see below) shows the values and the reference values for each of the remaining validities. 


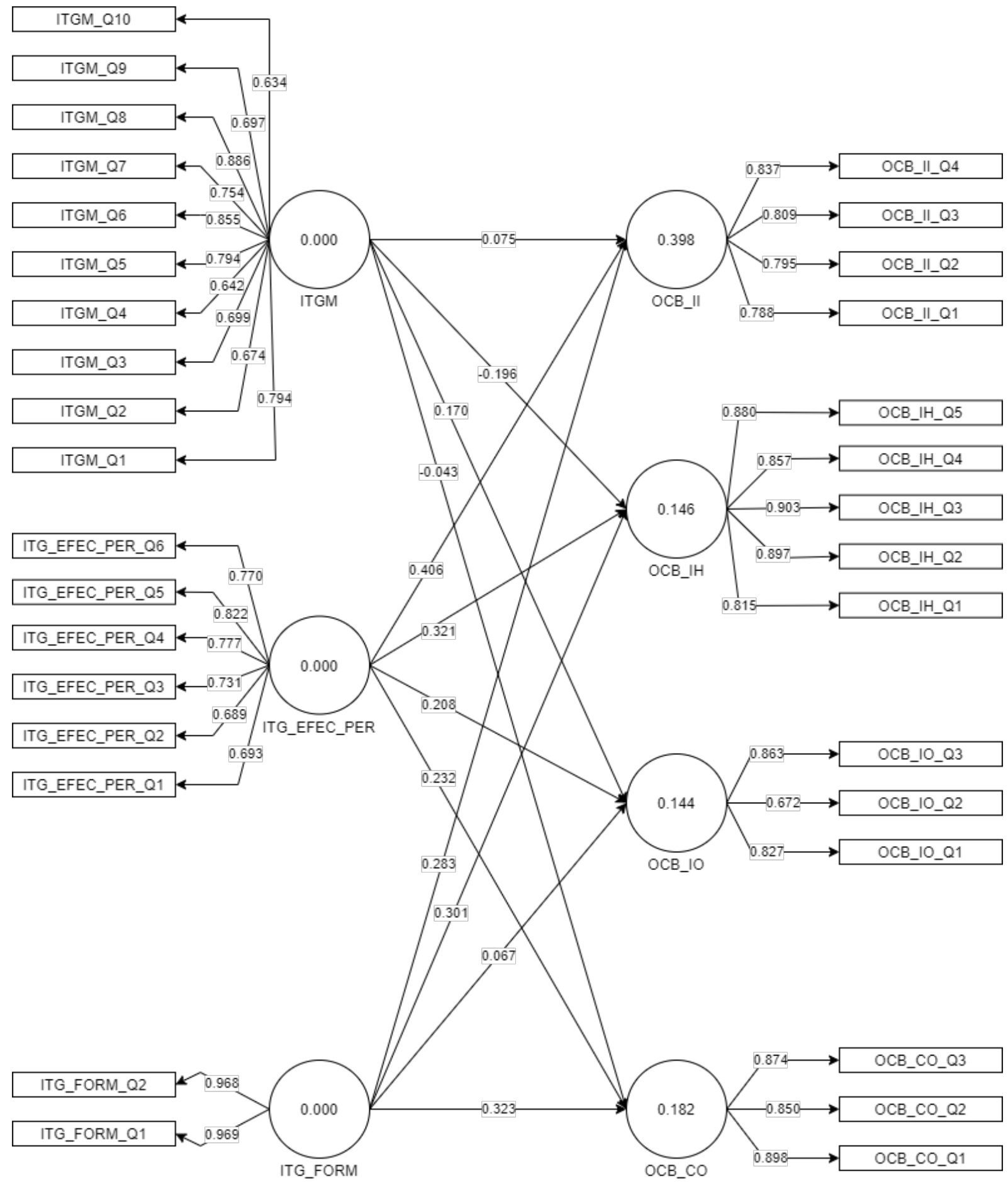

Figure 4. The first-order model

The instrument successfully passes both discriminant and convergent validity and shows internal consistency, which means that it is suitable for this study's expectations. To make it possible to test the researched hypotheses, a Second-order Measurement Model was carried out following the recommendations of Jr., M. Hult, et al. (2014) and Sanchez (2013). As a result of the first-order model's calculations, the values of the latent variables ITGM, ITG_EFEC_PER, and ITG_FORM were loaded into a new data file to represent the observable 
variables of the new latent variable ITG_INST (ITG institutionalization model). Figure 5 (see below) presents the second-order model.

\begin{tabular}{|c|c|c|c|c|c|c|c|}
\hline & ITGM & ITG_EFEC_PER & ITG_FORM & OCB_CO & OCB_IH & OCB_II & OCB_IO \\
\hline ITGM_Q1 & 0.794 & 0.381 & 0.537 & -0.162 & -0.106 & 0.346 & 0.249 \\
\hline ITGM_Q2 & 0.674 & 0.386 & 0.457 & -0.149 & -0.115 & 0.211 & 0.156 \\
\hline ITGM_Q3 & 0.699 & 0.297 & 0.450 & -0.200 & -0.089 & 0.298 & 0.200 \\
\hline ITGM_Q4 & 0.642 & 0.405 & 0.446 & -0.186 & -0.067 & 0.214 & 0.195 \\
\hline ITGM_Q5 & 0.794 & 0.434 & 0.487 & -0.177 & -0.075 & 0.309 & 0.268 \\
\hline ITGM_Q6 & 0.855 & 0.528 & 0.539 & -0.301 & -0.163 & 0.357 & 0.198 \\
\hline ITGM_Q7 & 0.754 & 0.289 & 0.556 & -0.292 & -0.163 & 0.353 & 0.125 \\
\hline ITGM_Q8 & 0.886 & 0.620 & 0.561 & -0.245 & -0.135 & 0.430 & 0.352 \\
\hline ITGM_Q9 & 0.697 & 0.301 & 0.613 & -0.290 & -0.258 & 0.416 & 0.281 \\
\hline ITGM_Q10 & 0.634 & 0.605 & 0.414 & -0.251 & -0.202 & 0.591 & 0.355 \\
\hline ITG_EFEC_PER_Q1 & 0.244 & 0.693 & 0.132 & -0.272 & -0.265 & 0.357 & 0.206 \\
\hline ITG_EFEC_PER_Q2 & 0.512 & 0.689 & 0.323 & -0.322 & -0.249 & 0.457 & 0.159 \\
\hline ITG_EFEC_PER_Q3 & 0.546 & 0.731 & 0.337 & -0.186 & -0.134 & 0.438 & 0.329 \\
\hline ITG_EFEC_PER_Q4 & 0.546 & 0.777 & 0.301 & -0.126 & -0.135 & 0.318 & 0.293 \\
\hline ITG_EFEC_PER_Q5 & 0.338 & 0.822 & 0.263 & -0.270 & -0.356 & 0.498 & 0.271 \\
\hline ITG_EFEC_PER_Q6 & 0.505 & 0.770 & 0.258 & -0.233 & -0.215 & 0.360 & 0.241 \\
\hline ITG_FORM_Q1 & 0.666 & 0.324 & 0.969 & -0.353 & -0.288 & 0.471 & 0.264 \\
\hline ITG_FORM_Q2 & 0.659 & 0.373 & 0.968 & -0.376 & -0.258 & 0.460 & 0.235 \\
\hline OCB_CO_Q1 & -0.336 & -0.311 & -0.370 & 0.874 & 0.657 & -0.630 & -0.259 \\
\hline OCB_CO_Q2 & -0.177 & -0.197 & -0.211 & 0.850 & 0.624 & -0.536 & -0.098 \\
\hline OCB_CO_Q3 & -0.274 & -0.305 & -0.362 & 0.898 & 0.712 & -0.556 & -0.191 \\
\hline OCB_IH_Q1 & -0.187 & -0.284 & -0.227 & 0.599 & 0.815 & -0.474 & -0.178 \\
\hline OCB_IH_Q2 & -0.151 & -0.262 & -0.301 & 0.679 & 0.897 & -0.555 & -0.102 \\
\hline OCB_IH_Q3 & -0.244 & -0.298 & -0.280 & 0.735 & 0.903 & -0.561 & -0.136 \\
\hline OCB_IH_Q4 & -0.162 & -0.262 & -0.193 & 0.616 & 0.857 & -0.454 & -0.177 \\
\hline OCB_IH_Q5 & -0.122 & -0.260 & -0.211 & 0.690 & 0.880 & -0.519 & -0.098 \\
\hline OCB_II_Q1 & 0.509 & 0.591 & 0.381 & -0.567 & -0.483 & 0.788 & 0.315 \\
\hline OCB_II_Q2 & 0.405 & 0.400 & 0.472 & -0.449 & -0.404 & 0.795 & 0.322 \\
\hline OCB_II_Q3 & 0.320 & 0.358 & 0.346 & -0.543 & -0.543 & 0.809 & 0.403 \\
\hline OCB_II_Q4 & 0.361 & 0.374 & 0.334 & -0.571 & -0.487 & 0.837 & 0.371 \\
\hline OCB_IO_Q1 & 0.267 & 0.242 & 0.154 & -0.209 & -0.147 & 0.418 & 0.827 \\
\hline OCB_IO_Q2 & 0.138 & 0.171 & 0.084 & -0.150 & -0.151 & 0.218 & 0.672 \\
\hline OCB_IO_Q3 & 0.340 & 0.333 & 0.304 & -0.175 & -0.102 & 0.361 & 0.863 \\
\hline
\end{tabular}

Table 7. Discriminant validity - Cross loading analysis for the first-order mode

\begin{tabular}{|l|c|c|c|c|c|c|c|}
\hline & ITGM & ITG_EFEC_PER & ITG_FORM & OCB_CO & OCB_IH & OCB_II & OCB_IO \\
\hline ITGM & $\mathbf{0 . 7 4 8}$ & & & & & & \\
\hline ITG_EFEC_PER & 0.591 & $\mathbf{0 . 7 4 8}$ & & & & & \\
\hline ITG_FORM & 0.684 & 0.360 & $\mathbf{0 . 9 6 8}$ & & & & \\
\hline OCB_CO & -0.314 & -0.322 & -0.376 & $\mathbf{0 . 8 7 4}$ & & & \\
\hline OCB_IH & -0.199 & -0.313 & -0.282 & 0.764 & $\mathbf{0 . 8 7 1}$ & & \\
\hline OCB_II & 0.508 & 0.552 & 0.481 & -0.661 & -0.592 & $\mathbf{0 . 8 0 7}$ & \\
\hline OCB_IO & 0.338 & 0.332 & 0.258 & -0.223 & -0.156 & 0.432 & $\mathbf{0 . 7 9 2}$ \\
\hline
\end{tabular}

Table 8. Discriminant validity - Fornell-Larcker criterion for the first-order model 


\begin{tabular}{|l|l|l|l|}
\hline & Cronbach's Alpha & Composite Reliability & $\begin{array}{l}\text { Average Variance } \\
\text { Extracted (AVE) }\end{array}$ \\
\hline ITGM & 0.912 & 0.926 & 0.559 \\
\hline ITG_EFEC_PER & 0.843 & 0.884 & 0.560 \\
\hline ITG_FORM & 0.934 & 0.968 & 0.938 \\
\hline OCB_CO & 0.849 & 0.907 & 0.764 \\
\hline OCB_IH & 0.920 & 0.940 & 0.759 \\
\hline OCB_II & 0.824 & 0.882 & 0.652 \\
\hline OCB_IO & 0.720 & 0.833 & 0.627 \\
\hline Reference Values & CA $>\mathbf{0 . 7 0}$ & CR $>\mathbf{0 . 7 0}$ & AVE $>\mathbf{0 . 5 0}$ \\
\hline
\end{tabular}

Table 9. Convergent validity and internal model consistency for the first-order model

In order to perform a second-order model, it is necessary to re-evaluate the instrument by repeating the validations performed for the first-order model in the second-order model. Thus, Table 10 shows the discriminant validity test, considering the Cross Loading Analysis (Chin, 1998), and Table 11 shows the discriminant validity test, considering the Fornell \& Larcker (1981) criterion. Finally, Table 12 shows the convergent validity and Internal Consistency model following the reference values that Jr., C. Black, et al. (2014) recommend.

\begin{tabular}{|l|l|l|l|l|l|}
\hline & ITG_INST & OCB_CO & OCB_IH & OCB_II & OCB_IO \\
\hline ITG_EFEC_PER & $\mathbf{0 . 9 0 4}$ & -0.315 & -0.203 & 0.508 & 0.340 \\
\hline ITG_FORM & $\mathbf{0 . 7 9 3}$ & -0.322 & -0.315 & 0.552 & 0.334 \\
\hline ITGM & $\mathbf{0 . 8 0 6}$ & -0.377 & -0.282 & 0.481 & 0.261 \\
\hline OCB_CO_Q1 & -0.406 & $\mathbf{0 . 8 8 0}$ & 0.655 & -0.630 & -0.257 \\
\hline OCB_CO_Q2 & -0.234 & $\mathbf{0 . 8 4 8}$ & 0.624 & -0.535 & -0.097 \\
\hline OCB_CO_Q3 & -0.376 & $\mathbf{0 . 8 9 2}$ & 0.715 & -0.556 & -0.192 \\
\hline OCB_IH_Q1 & -0.281 & 0.598 & $\mathbf{0 . 8 2 0}$ & -0.474 & -0.177 \\
\hline OCB_IH_Q2 & -0.287 & 0.679 & $\mathbf{0 . 8 9 1}$ & -0.555 & -0.101 \\
\hline OCB_IH_Q3 & -0.330 & 0.733 & $\mathbf{0 . 9 1 0}$ & -0.561 & -0.135 \\
\hline OCB_IH_Q4 & -0.249 & 0.617 & $\mathbf{0 . 8 5 9}$ & -0.454 & -0.176 \\
\hline OCB_IH_Q5 & -0.240 & 0.690 & $\mathbf{0 . 8 7 3}$ & -0.519 & -0.097 \\
\hline OCB_II_Q1 & 0.596 & -0.567 & -0.486 & $\mathbf{0 . 7 8 7}$ & 0.316 \\
\hline OCB_II_Q2 & 0.510 & -0.451 & -0.400 & $\mathbf{0 . 7 9 6}$ & 0.323 \\
\hline OCB_II_Q3 & 0.410 & -0.544 & -0.542 & $\mathbf{0 . 8 0 9}$ & 0.400 \\
\hline OCB_II_Q4 & 0.429 & -0.572 & -0.488 & $\mathbf{0 . 8 3 7}$ & 0.372 \\
\hline OCB_IO_Q1 & 0.266 & -0.211 & -0.150 & 0.418 & $\mathbf{0 . 8 2 0}$ \\
\hline OCB_IO_Q2 & 0.159 & -0.151 & -0.152 & 0.218 & $\mathbf{0 . 6 6 2}$ \\
\hline OCB_IO_Q3 & 0.391 & -0.175 & -0.103 & 0.361 & $\mathbf{0 . 8 7 2}$ \\
\hline
\end{tabular}

Table 10. Discriminant validity - Cross loading analysis for the second-order model

\begin{tabular}{|l|c|c|c|c|c|}
\hline & ITG_INST & OCB_CO & OCB_IH & OCB_II & OCB_IO \\
\hline ITG_INST & $\mathbf{0 . 8 3 6}$ & & & & \\
\hline OCB_CO & -0.405 & $\mathbf{0 . 8 7 4}$ & & & \\
\hline OCB_IH & -0.322 & 0.764 & $\mathbf{0 . 8 7 1}$ & & \\
\hline OCB_II & 0.618 & -0.662 & -0.591 & $\mathbf{0 . 8 0 7}$ & \\
\hline OCB_IO & 0.375 & -0.223 & -0.157 & 0.432 & $\mathbf{0 . 7 9 0}$ \\
\hline
\end{tabular}

Table 11. Discriminant validity - Fornell-Larcker criterion for the second-order model 


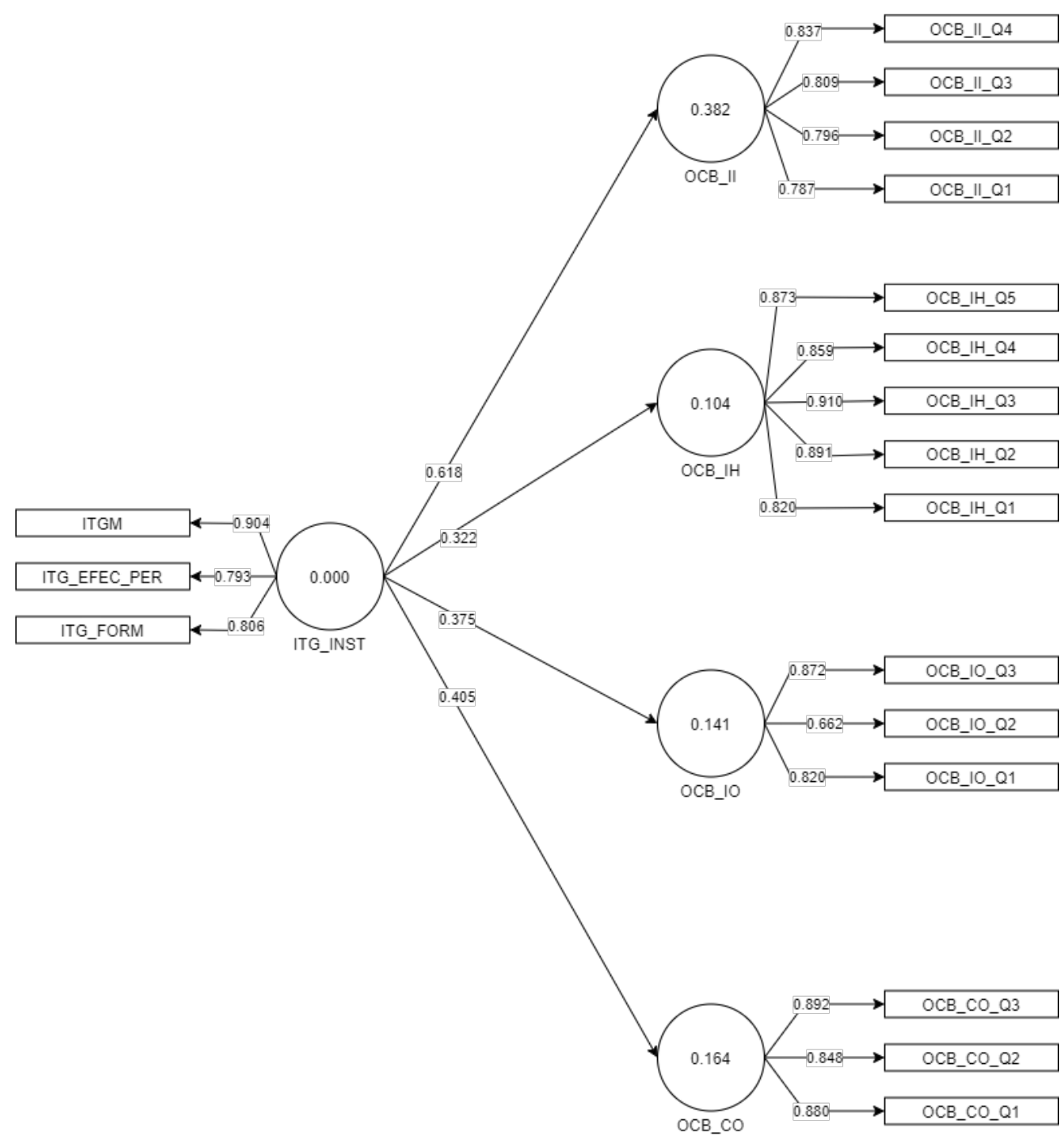

Figure 5. The second-order model

\begin{tabular}{|l|c|c|c|}
\hline & Cronbach's Alpha & Composite Reliability & Average Variance Extracted (AVE) \\
\hline ITG_INST & 0.782 & 0.781 & 0.699 \\
\hline OCB_CO & 0.849 & 0.887 & 0.764 \\
\hline OCB_IH & 0.920 & 0.930 & 0.759 \\
\hline OCB_II & 0.824 & 0.833 & 0.652 \\
\hline OCB_IO & 0.720 & 0.821 & 0.624 \\
\hline Reference Values & CA $>\mathbf{0 . 7 0}$ & CR $>\mathbf{0 . 7 0}$ & AVE $>\mathbf{0 . 5 0}$ \\
\hline
\end{tabular}

Table 12. Convergent validity and internal model consistency for the second-order model

Just as the first-order model, the second-order model successfully passes both discriminant and convergent validity and shows internal consistency, which means that it is suitable for this study's purpose.

\subsection{Analysis of the structural model}

With the assurance that the items and constructs are valid, the measurement model adjustments are finished. Then it is possible to start the analysis of the structural model, or in other words, the analysis of the research model hypothesis with the Pearson coefficient of 
determination $\left(\mathrm{R}^{2}\right)$, the student's t-test, the Stone-Geisser indicator $\left(\mathrm{Q}^{2}\right)$, and the Cohen indicator $\left(\mathrm{f}^{2}\right)$.

The analysis starts with the $\mathrm{R}^{2}$ (Hair et al., 2011). The $\mathrm{R}^{2}$ evaluates the predictable proportion of variance that the independent variable has on the dependent variable, which measures the model's predictive accuracy (Hair Jr. et al., 2014). Table 13 shows the values of the $\mathrm{R}^{2}$.

\begin{tabular}{|l|l|}
\hline \multicolumn{2}{|c|}{} \\
\hline OCB_IO & 0.141 \\
\hline OCB_II & 0.382 \\
\hline OCB_IH & 0.104 \\
\hline OCB_CO & 0.164 \\
\hline
\end{tabular}

Table 13. Coefficient of determination $\left(R^{2}\right)$

Cohen (1988) suggests that, for the area of social and behavioral science, values such as $\mathrm{R}^{2}>$ $0.26, \mathrm{R}^{2}>0.13$, and $\mathrm{R}^{2}>0.0196$ are described as having a substantial, moderate, or weak amount of correlation. For example, the coefficient of determination, $\mathrm{R}^{2}$, is 0.382 for the OCB_II endogenous latent variable, which means that the latent variable ITG_INST substantially explains $38.2 \%$ of the variance OCB_II (Wong, 2013).

The next step of this analysis is to test the significance and the effects of the relationships pointed out between the latent variable ITG_INST and the OCB model's four latent variables. These data resulted from the SmartPLS software, which used the bootstrapping module to calculate the student's t-test between the original values of the data and those obtained by the resampling technique (Ringle et al., 2014). Table 14 presents the path coefficients and $\mathrm{t}$-test values.

\begin{tabular}{|l|l|l|l|l|}
\hline & Original Sample (O) & Sample Mean (M) & $\begin{array}{l}\text { Standard Deviation } \\
\text { (STDEV) }\end{array}$ & T Statistics \\
\hline ITG_INST -> OCB_IO & 0.375 & 0.394 & 0.079 & 4.755 \\
\hline ITG_INST -> OCB_II & 0.618 & 0.625 & 0.057 & 10.854 \\
\hline ITG_INST -> OCB_IH & 0.322 & 0.336 & 0.080 & 4.021 \\
\hline ITG_INST -> OCB_CO & 0.405 & 0.415 & 0.071 & 5.695 \\
\hline
\end{tabular}

Table 14. Test of significance of the relations between ITG institutionalization and OCB

Looking at the last column of Table 14, it is possible to verify that the values of the t-test are higher than 1.96, which corresponds to $\mathrm{p}$-values $\leq 0.05$ (a p-value is a number between 0 and 1 that helps to determine the significance of the results (Rumsey, 2006)). This means that all the relations studied are significant. Finally, Table 15 shows the values of the last two adjustment quality indicators of the analyzed model: the Predictive Validity through the Stone-Geisser indicator $\left(\mathrm{Q}^{2}\right)$ and the Effect Size through the Cohen Indicator $\left(\mathrm{f}^{2}\right)$ (Ringle et al., 2014).

\begin{tabular}{|l|l|l|}
\hline & \left. Stone-Geiss ${\left(\mathbf{Q}^{2}\right)}\right)$ & Cohen $\left(\mathbf{f}^{2}\right)$ \\
\hline OCB_IO & 0.065 & 0.163 \\
\hline OCB_II & 0.222 & 0.617 \\
\hline OCB_IH & 0.069 & 0.116 \\
\hline OCB_CO & 0.104 & 0.197 \\
\hline
\end{tabular}

Table 15. The model's predictive validity and constructs effects 
The $\mathrm{Q}^{2}$ indicator examines the model's accuracy and predictive relevance and is obtained by the Blindfolding procedure in SmartPLS. By analyzing the $\mathrm{Q}^{2}$ indicator values, it is possible to verify that the values are above zero. This shows that the exogenous construct has predictive relevance for the endogenous construct under discussion (Hair et al., 2011; Hair Jr. et al., 2014).

Finally, this section analyzes the $\mathrm{f}^{2}$ indicator values that evaluate each construct's contribution to the model's adjustment. According to Cohen (1988), for the social and behavioral sciences, values such as $\mathrm{f}^{2}>0.02, \mathrm{f}^{2}>0.15$, and $\mathrm{f}^{2}>0.36$ are considered to have a small, medium, or large effect, respectively. Thus, all the latent variables are essential for the model's application.

\section{Discussion and conclusion}

This study is intended to analyze the effects of adopting IT Governance mechanisms on individuals' behavior in Portuguese organizations regarding their organizational citizenship behavior. Table 14 shows the existence of significant relations ( $p$-values $\leq 0.05$ ) between ITG institutionalization and the OCB variables. This confirms the study's general hypothesis that ITG institutionalization positively affects individuals' OCBs in Portuguese organizations.

This study's general hypothesis is composed of four confirmed hypotheses. Thus, for each one of them, based on the results of this study, it is possible to make predictions that ITG institutionalization will increase: (1) conscientiousness behavior, (2) interpersonal harmony behavior, (3) identification with the organization behavior, and (4) individual initiative behavior.

- H1: Conscientiousness behavior increased up to $41 \%$ ( $\beta=0.405$; p-value $\leq 0.05)$. Characterized as high-power distance and low-performance orientation, the Portuguese culture is affected by the process's institutionalization and structure mechanisms. As a result, Portuguese employees have greater compliance with organizational rules and issues related to the organization's internal maintenance.

- H2: Interpersonal harmony behavior increased up to $32 \%(\beta=0.322 ; \mathrm{p}$-value $\leq 0.05)$. This behavior is characterized by the participation of individuals sharing knowledge and experiences. Due to this, it was expected to work well with the ITG institutionalization, which eventually happened.

- H3: Identification with the organization behavior increased up to $38 \%$ ( $\beta=0.375$; $p$-value $\leq$ 0.05). This indicator supports that ITG institutionalization will instigate individuals to defend the organization's name with attitudes that dignify its image in front of people from outside the organization.

- H4: Individual initiative behavior increased up to $62 \%$ ( $\beta=0.618$; $p$-value $\leq 0.05)$. ITG institutionalization supports relational mechanisms that promote communication with other people in the workplace to improve individual and group performance. This is reinforced by Portuguese culture as Portugal is characterized as a collectivist and feminine society, where people value equality, solidarity, and quality in their professional lives.

Several conclusions can be drawn from these results. On the one hand, looking at the theoretical path, it is possible to reinforce the validity of the model proposed by Wiedenhöft et al. (2017). This reinforcement is also essential to separately fortify the validity of the OCB construct proposed by Arménio Rego (1999) and the ITG institutionalization constructs proposed by Luciano et al. (2016) and Wiedenhöft et al. (2017), showing the existence of a 
significant and positive relationship between them. On the other hand, P. M. Podsakoff et al. (1997) empirically demonstrates that organizations with better OCBs show better effectiveness indicators. In practice, this contributes to Portuguese organizations showing that implementing their ITG mechanisms increases employees' OCBs and, consequently, organizational effectiveness.

\subsection{Comparing results}

The conclusions drawn from this study of Portuguese workers from public and private companies can be compared to Wiedenhöft et al.'s (2017) results, which were obtained from the analysis of Brazilian civil servants, by contrasting the values of the significance tests and effects of the relationships pointed out between the latent variable ITG_INST and the OCB model's four latent variables as presented in Table 14.

The data presented in Table 16 shows that the ITG institutionalization model has different effect levels on individuals' OCBs from Portugal (PT) and Brazil (BR). With this, it is possible to see how the cultural context impacts individuals' behavior. Even if there is some parallelism between the Brazilian and Portuguese cultures regarding Hofstede's (2011) variables, the cultural context indeed affects citizenship behavior dimensions. These results show that only the values related to the dimension "identification with the organization" are similar in both cultures. This is because Portugal and Brazil are two collectivist countries, where employees may improve behaviors that benefit the organization rather than behaviors that benefit themselves, typical in individualistic cultures. In contrast, but consistent with the data presented, the institutionalization of ITG seems to have a better impact on the other three dimensions in the Portuguese context since the remaining values are lower in the Brazilian context.

\begin{tabular}{|l|c|c|c|c|c|c|c|c|}
\hline & \multicolumn{2}{|c|}{ Original Sample (O) } & \multicolumn{2}{c|}{ Sample Mean (M) } & \multicolumn{2}{c|}{ Standard Deviation (STDEV) } & \multicolumn{2}{c|}{ T Statistics } \\
\cline { 2 - 9 } & PT & BR & PT & BR & PT & BR & PT & BR \\
\hline ITG_INST -> OCB_IO & 0.375 & 0.3571 & 0.394 & 0.3645 & 0.079 & 0.0590 & 4.755 & 6.0541 \\
\hline ITG_INST -> OCB_II & 0.618 & 0.5410 & 0.625 & 0.5443 & 0.057 & 0.0538 & 10.854 & 10.592 \\
\hline ITG_INST -> OCB_IH & 0.322 & 0.2091 & 0.336 & 0.2262 & 0.080 & 0.0637 & 4.021 & 3.2815 \\
\hline ITG_INST -> OCB_CO & 0.405 & 0.2429 & 0.415 & 0.2529 & 0.071 & 0.0647 & 5.695 & 3.7525 \\
\hline
\end{tabular}

Table 16. Significance of the relations between ITG institutionalization and OCB in this study in Portugal (PT) and in Wiedenhöft et al.'s (2017) study in Brazil (BR)

\subsection{Limitations and Future Research}

While relevant, these results should be interpreted with caution since this research was subjected to some overall constraints. On the one hand, the sample size is not especially large, making generalizations difficult and precluding a pre-test on the instrument used. Despite this limitation, it was possible to meet the minimum requirements of the research techniques applied in the study. On the other hand, not all relevant industries are presented in the survey, and according to the contingency factors of ITG institutionalization, this could be important. Therefore, further studies must try to understand the role that ITG institutionalization plays in OCB.

Future studies may collect more results to improve the conclusions of this study. It should be recognized that ITG might impact differently on individual behaviors depending on the individual's role in an organizational hierarchy. This was the second time that the model 
relating ITG institutionalization and the OCB were used and validated. In both studies, individual initiative behavior has a higher positive effect than the other behaviors. Future research using the same model should consider if and how the model applies in other countries as well as look into specific types of organizations. If this relationship between ITG institutionalization and individual initiative behavior remains significant, further research should investigate the main reasons for this outcome.

\section{References}

Amali, L. N., Hadjaratie, L., \& Suhada, S. (2018). The Influence of Organizational Culture in Application of Information Technology Governance. Journal of Information Systems Engineering and Business Intelligence, 4(1), 1. https://doi.org/10.20473/jisebi.4.1.1-10

Bartenschlager, J., \& Goeken, M. (2010). IT strategy implementation framework - Bridging enterprise architecture and IT governance. 16th Americas Conference on Information Systems 2010, AMCIS 2010, 1, 379-388. https://aisel.aisnet.org/amcis2010/400

Borges-Andrade, J. E. (1994). Conceptualizing and measuring organizational commitment. 1.

Brandi, L. S. N., \& Malheiro da Silva, A. (2017). Contributions to a comparative study Brazil and Portugal: management of information systems and technologies. Prisma.Com, 33, $3-$ 32. https://doi.org/10.21747/16463153/33a1

Brief, A. P., \& Motowidlo, S. J. (1986). Prosocial Organizational Behaviors. The Academy of Management Review, 11(4), 1689-1699. https://doi.org/10.1017/CBO9781107415324.004

Brown, C. V., \& Magill, S. L. (1994). Alignment of the IS Functions with the Enterprise: Toward a Model of Antecedents. MIS Quarterly, 18(4), 371. https://doi.org/10.2307/249521

Chin, W. W. (1998). The partial least squares approach for structural equation modeling. In Modern methods for business research.

Cohen, J. (1988). Statistical Power Analysis for the Behavioral Sciences. In Fibre Chemistry (Vol. 15, Issue 6). https://doi.org/10.1007/BF00544941

Curts, E. (2013). Using Google Forms. Creative Commons Attribution, 1-12.

De Haes, S., \& Van Grembergen, W. (2004). IT Governance and Its Mechanisms. Isaca. https://doi.org/citeulike-article-id:9755150

De Haes, S., \& Van Grembergen, W. (2008). Analysing the relationship between IT governance and business/IT alignment maturity. Proceedings of the Annual Hawaii International Conference on System Sciences, 1-10. https://doi.org/10.1109/HICSS.2008.66

De Haes, S., Van Grembergen, W., Anant, J., \& Huygh, T. (2020). Enterprise Governance of Information Technology. Achieving Alignment and Value in Digital Organizations. In Springer.

Deetz, S. (1996). Crossroads - Describing Differences in Approaches to Organization Science : Rethinking Burrell and Morgan and Their Legacy. Organization Science 7, 191-207.

Ferreira, A. I., Braun, T., \& Sydow, J. (2013). Citizenship behavior in project-based organizing: Comparing German and Portuguese project managers. International Journal of Human Resource Management, 24(20), 3772-3793. https://doi.org/10.1080/09585192.2013.777937 
Field, A. (2009). Discovering Statistics Using SPSS (and sex and drugs and rock' $n^{\prime}$ roll).

Fornell, C., \& Larcker, D. F. (1981). Evaluating Structural Equation Models with Unobservable Variables and Measurement Error. Journal of Marketing Research, 18(1), 39. https://doi.org/10.2307/3151312

Graham, J. W. (1991). An essay on organizational citizenship behavior. Employee Responsibilities and Rights Journal, 4(4), 249-270. https://doi.org/10.1007/BF01385031

Hair, J. F., Ringle, C. M., \& Sarstedt, M. (2011). PLS-SEM: Indeed a silver bullet. Journal of Marketing Theory and Practice, 19(2), 139-152. https://doi.org/10.2753/MTP10696679190202

Hair Jr., J. F., C. Black, W., J. Babin, B., \& E. Anderson, R. (2018). Multivariate Data Analysis. In Neuromarketing in India: Understanding the Indian Consumer. https://doi.org/10.4324/9781351269360

Hair Jr., J. F., Hult, G. T. M., Ringle, C. M., \& Sarstedt, M. (2014). A Primer on Partial Least Squares Structural Equation Modeling (PLS-SEM).

Hardy, G. (2006). Using IT governance and COBIT to deliver value with IT and respond to legal, regulatory and compliance challenges. Information Security Technical Report, 55-61. https://doi.org/10.1016/j.istr.2005.12.004

Hofstede, G. (1989). Organising for Cultural Diversity. European Management Journal, 7(4), 390397. https://doi.org/10.1016/0263-2373(89)90075-3

Hofstede, G. (2011). Dimensionalizing Cultures: The Hofstede Model in Context. Online Readings in Psychology and Culture, 2(1), 1-26. https://doi.org/10.9707/2307-0919.1014

Huang, R., Zmud, R. W., \& Price, R. L. (2010). Influencing the effectiveness of IT governance practices through steering committees and communication policies. European Journal of Information Systems, 19(3), 288-302. https://doi.org/10.1057/ejis.2010.16

ITGI. (2003). Board Briefing on IT Governance. In IT Governance Institute.

Jacobson, D. D. (2009). Revisiting IT Governance in the Light of Institutional Theory. Proceedings of the 42nd Hawaii International Conference on System Sciences. http://scholarcommons.usf.edu/etd/6469

Jesuino, J. C. (2002). Latin Europe cluster: From south to north. Journal of World Business, 37(1), 81-89. https://doi.org/10.1016/S1090-9516(01)00076-1

Juiz, C., Guerrero, C., \& Lera, I. (2014). Implementing Good Governance Principles for the Public Sector in Information Technology Governance Frameworks Carlos. 2014(January), 9-27.

Juiz, C., \& Toomey, M. (2015). To govern IT, or not to govern IT? Communications of the ACM, 58(2), 58-64. https://doi.org/10.1145/2656385

Katz, D., \& Kahn, R. L. (1978). The Social Psychology of Organizations. New York: Wiley. https://doi.org/10.1177/003803857200600313

Kowal, J., Keplinger, A., \& Mäkiö, J. (2019). Organizational citizenship behavior of IT professionals: lessons from Poland and Germany. Information Technology for Development, 25(2), 227-249. https://doi.org/10.1080/02681102.2018.1508402 
Loh, L., \& Venkatraman, N. (1992). Diffusion of IT outsourcing: influence sources and the Kodak effect. Information Systems Research, 3(4). http://search.ebscohost.com/login.aspx?direct=true\&db=epref\&AN=ISR.C.CCD.LOH.D IOISK\&site=bsi-live DP - EBSCOhost DB - epref

Luciano, E. M., Wiedenhöft, G. C., Macadar, M. A., \& Pinheiro dos Santos, F. (2016). Information Technology Governance Adoption: Understanding its Expectations Through the Lens of Organizational Citizenship Behaviour. International Journal of IT/Business Alignment and Governance, 7(2), 22-32. https://doi.org/10.4018/IJITBAG.2016070102

Lunardi, G. L., Becker, J. L., \& Macada, A. C. G. (2009). The Financial Impact of IT Governance Mechanisms Adoption: An Empirical Analysis with Brazilian Firms. Nd Hawaii International Conference on System Sciences, 1-10. https://doi.org/10.1109/HICSS.2009.434

Matias Siqueira, M. M. (2002). Measures of organizational behavior. 7, 11-18. http://www.scielo.br/pdf/epsic/v7nspe/a03v7esp.pdf

Organ, D. W. (1988). Organizational Citizenship Behavior: The Good Soldier Syndrome. In The Academy of Management Review (Vol. 14, Issue 2).

Organ, D. W. (1997). Organizational Citizenship Behavior: It's Construct Clean-Up Time. Human Performance, 10(2), 85-97. https://doi.org/10.1207/s15327043hup1002

Pereira, R., Almeida, R., \& Mira da Silva, M. (2014). IT Governance Patterns in the Portuguese Financial Industry. Hawaii International Conference on System Science IT, 96(24), 1369713702. https://doi.org/10.1109/HICSS.2014.541

Pereira, R., \& Mira da Silva, M. (2012). A LITERATURE REVIEW: GUIDELINES AND CONTINGENCY FACTORS FOR IT GOVERNANCE. European, Mediterranean $\mathcal{E}$ Middle Eastern Conference on Information Systems 2012, 2012, 342-360.

Pereira, R., \& Mira da Silva, M. (2012a). Designing a New Integrated IT Governance and IT Management Framework Based on Both Scientific and Practitioner Viewpoint Article. International Journal of Enterprise Information Systems, October, 191-200. https://doi.org/10.1109/EDOC.2012.30

Pereira, R., \& Mira da Silva, M. (2012b). IT Governance Implementation: The Determinant Factors. Communications of the IBIMA, September 2014, 1-16. https://doi.org/10.5171/2012.970363

Podsakoff, N. P., Podsakoff, P. M., MacKenzie, S. B., Maynes, T. D., \& Spoelma, T. M. (2014). Consequences of unit-level organizational citizenship behaviors: A review and recommendations for future research. Journal of Organizational Behavior, 35(S1), 87-119. https://doi.org/10.1002/job

Podsakoff, P. M., Ahearne, M., \& MacKenzie, S. B. (1997). Organizational Citizenship Behavior and the Quantity and Quality of Work Group Performance. Journal of Applied Psychology, 82(2), 262-270. http://papers.ssrn.com/sol3/papers.cfm?abstract_id=1584824

Podsakoff, P. M., \& MacKenzie, S. B. (1997). Impact of Organizational Citizenship Behavior on Organizational Performance: A Review and Suggestion for Future Research. Human Performance, 10(2), 133-151. https://doi.org/10.1207/s15327043hup1002 
Podsakoff, P. M., MacKenzie, S. B., Paine, J. B., \& Bachrach, D. G. (2000). Organizational Citizenship Behaviors: A Critical Review of the Theoretical and Empirical Literature and Suggestions for Future Research. Journal of Management, 26(3), 513-563. https://doi.org/10.1177/014920630002600307

Ponto, J. (2015). Understanding and Evaluating Survey Research. Journal of the Advanced Practitioner in Oncology, 6(2), 168-16871.

Rego, A. (1999). Organizational citizenship behaviors: operationalizing a construct. Psicologia, 13(1-2), 127-148. https://doi.org/10.17575/rpsicol.v13i1/2.563

Rego, A. (2002). Ethical Climates and Organizational Citizenship Behaviors. Revista de Administraçao de Empresas, 42(1), 50-63.

Rego, A. A., Pina, M., \& Pina e Cunha, M. (2010). Organizational justice and citizenship behaviors: A study in the Portuguese cultural context. Applied Psychology: An International Review, 59(3), 404-430. https://doi.org/10.1111/j.1464-0597.2009.00405.x3

Rego, A., \& Pina e Cunha, M. (2008). Organisational citizenship behaviours and effectiveness: An empirical study in two small insurance companies. Service Industries Journal, 28(4), 541-554. https://doi.org/10.1080/02642060801917695

Ringle, C. M., da Silva, D., \& Bido, D. (2014). Structural Equation Modeling with the SMARTPLS. REMark - Revista Brasileira de Marketing, 13, 56-73. https://doi.org/10.5585/remark.v13i2.2717

Rumsey, D. (2006). Statistics Essentials For Dummies. In Wiley Publishing (Vol. 11, Issues 1 P.1446). https://doi.org/10.2741/1775

Sambamurthy, V., \& Zmud, R. W. (1999). Arrangements for Information Technology Governance: A Theory of Multiple Contingencies. MIS Quarterly, 23(2), 261-290.

Sanchez, G. (2013). PLS Path Modeling with R.

Schwarz, A., \& Hirschheim, R. (2003). An extended platform logic perspective of IT governance: Managing perceptions and activities of IT. Journal of Strategic Information Systems, 12(2), 129-166. https://doi.org/10.1016/S0963-8687(03)00021-0

Scott, W. R. (2008). Approaching adulthood: The maturing of institutional theory. Theory and Society, 37(5), 427-442. https://doi.org/10.1007/s11186-008-9067-z

Siqueira, M. M. M. (2003). Proposition and analysis of a model for organizational citizenship behaviors. Revista de Administração Contemporânea, 7(spe), 165-184. https://doi.org/10.1590/S1415-65552003000500009

Smith, C. A., Organ, D. W., \& Near, J. P. (1983). Organizational Citizenship Behavior: Its Nature and Antecedents. Journal of Applied Psychology, 68(4), 653-663.

Tiwana, A., \& Kim, S. K. (2015). Discriminating IT governance. Information Systems Research, 26(4), 656-674. https://doi.org/10.1287/isre.2015.0591

Tiwana, A., Konsynski, B., \& Venkatraman, N. (2013). Special Issue: Information Technology and Organizational Governance: The IT Governance Cube. Journal of Management Information Systems, 30(3), 7-12. https://doi.org/10.2753/MIS0742-1222300301 
Van Grembergen, W. (2004). Strategies for Information Technology Governance. https://doi.org/10.4018/978-1-59140-140-7

Van Grembergen, W., \& De Haes, S. (2018). Introduction to the Minitrack on IT Governance and its Mechanisms. 51st Hawaii International Conference on System Sciences (Hicss), 48774879. https://doi.org/10.1109/hicss.2014.535

Van Grembergen, W., De Haes, S., \& Guldentops, E. (2004). Structures, Processes and Relational Mechanisms for IT Governance. October.

Venkatesh, V., Brown, S. A., \& Bala, H. (2013). Bridging the Qualitative-Quantitative Divide: Guidelines for Conducting Mixed Methods Research in Information Systems. MIS Quarterly, 37(1), 21-54. https://doi.org/10.1080/14767430.2018.1454705

Visser, P. S., Krosnick, J. A., \& Lavrakas, P. J. (1986). Survey Research.

Webb, P., Pollard, C., \& Ridley, G. (2006). Attempting to Define IT Governance: Wisdom or Folly? Proceedings of the 39th Hawaii International Conference on System Sciences, 00(C), 661676. https://doi.org/10.1017/CBO9780511790423.026

Weill, P., \& Ross, J. W. (2004). IT Governance How Top Performers Manage IT Decision Rights for Superior Results. IT Governance, Boston: Ha(Harvard Business School Press Boston, Massachusetts), 1-10. https://doi.org/10.2139/ssrn.664612

Weisinger, J. Y., \& Trauth, E. M. (2003). The Importance of Situating Culture in Cross-Cultural IT Management. IEEE Transactions on Engineering Management, 50(1), 26-30. https://doi.org/10.1109/TEM.2002.808259

Wiedenhöft, G. C., Luciano, E. M., \& Pereira, G. V. (2019). Information Technology Governance Institutionalization and the Behavior of Individuals in the Context of Public Organizations. Information Systems Frontiers, 2017, 1453-1467. https://doi.org/10.1007/s10796-019-09945-7

Wiedenhöft, G. C, Luciano, E. M., \& Pereira, G. V.. (2017). Institutionalization of Information Technology Governance and the Behavior of Individuals in the Public Organizations Context. ECIS, 2017, 1453-1467.

Wong, K. K.-K. (2013). Partial Least Squares Structural Equation Modeling (PLS-SEM) Techniques Using SmartPLS. Marketing Bulletin, 24(1), 1-32. http://marketingbulletin.massey.ac.nz/v24/mb_v24_t1_wong.pdf\%5Cnhttp://www.researchgate.net/pro file/Ken_Wong10/publication/268449353_Partial_Least_Squares_Structural_Equation_ Modeling_(PLS-

SEM)_Techniques_Using_SmartPLS/links/54773b1b0cf293e2da25e3f3.pdf

Zhong, X., Aoun, C., \& Vatanasakdakul, S. (2012). Does culture matter? cultural influences and it governance integration mechanisms. 18th Americas Conference on Information Systems 2012, AMCIS 2012, 2.

Copyright: (c) 2021 authors. This is an open-access article distributed under the terms of the Creative Commons Attribution-NonCommercial 3.0 Australia License, which permits noncommercial use, distribution, and reproduction in any medium, provided the original author and AJIS are credited. 
doi: https://doi.org/10.3127/ajis.v25i0.3141

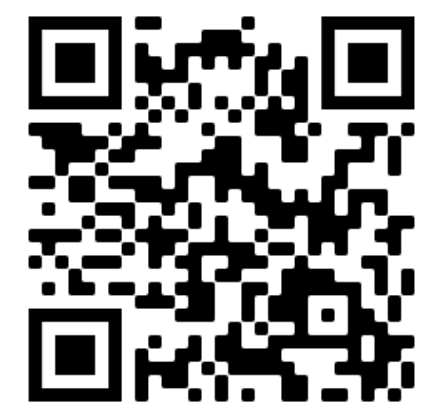

